\title{
Periorbital changes in patients with Poly(Lactic Acid/ Caprolactone) threads for brow augmentation
}

\author{
Phoebe Kar Wai Lam, MBChB (Otago), MRCS, MScPD (Cardiff) ${ }^{1}$ iD, Wang Lung Luk, MBBS (HK), MSc ${ }^{2}$ iD \\ ${ }^{1}$ Perfect Skin Solution, Hong Kong, ${ }^{2}$ Dr. Luk \& Partners, Hong Kong
}

\begin{abstract}
Background: Overlooked compensatory brow ptosis can lead to patients dissatisfaction and poor surgical results.
Objective: To evaluate the quantitative changes in periorbital dimensions in 11 patients with mild to moderate brow ptosis after browlift with Poly(Lactic Acid/Caprolactone) (P[LA/CL]) sutures.

Method: Retrospective analysis and data collected from reviewing clinical records, 11 patients, with mild to moderate brow ptosis, whom only has $\mathrm{P}(\mathrm{LA} / \mathrm{CL})$ browlift, fulfilled the criteria and included in the analysis. All patients had 2-dimensional clinical photos and 3 -dimensional clinical pictures in 5 standard views at baseline and follow-up. All periorbital measurements determined by the computer and collected for analysis.

Results: There was a significant difference in all periorbital measurements at 4 to 6 months' follow-up when compared with baseline $(p<0.05)$. Moderate lifting refers to changes in brow height of at least $2 \mathrm{~mm}$ at follow-up. A higher proportion of patients with moderate brow lift were able to achieve moderate lifting compared with mild brow ptosis. Moderate lifting is observed in $30 \%$ to $60 \%$ medial brow and $45 \%$ to $60 \%$ lateral brow for patients with moderate brow ptosis compared with $25 \%$ in those with mild brow ptosis. Infection, significant bruising, or scarring did not occur. Transient side effects, such as bruising and dimpling, eventually resolved.

Conclusion: Preoperative examination is vital to identify pre-existing compensatory brow ptosis. $\mathrm{P}(\mathrm{LA} / \mathrm{CL})$ thread-lifting for brow augmentation is a simple and effective procedure which can be used as an adjunct to upper eyelid surgery to prevent secondary brow ptosis following eyelid surgery and in turn, improve patients' satisfaction.
\end{abstract}

Keywords: brow ptosis; face lift; periorbital rejuvenation; thread lifting

\section{Introduction}

When formulating a treatment plan for an ageing upper face and when planning for upper eyelid surgery, various pathophysiological processes are at play. Evaluation of the brow position and brow-lid continuum is essential, should be careful particularly in detecting and documenting any asymmetry in the brow position.

Fine-tuning or correcting the asymmetry of the eyelid(s) and eyebrow(s) is possible with brow suture lifting by adjusting the entry/exit points and the angles according to the vector directions of thread lifting. The longevity of the thread is dependent upon its composite material, ranging from 6 to 24 months. As the material degrades, a fibrous capsule gradually forms around the suture thread, which strengthens the newly repositioned tissue sometimes after complete reabsorption of the thread material.

Brow lifting is more effective with good anchorage in the in- 
elastic aponeurotic fascia with elevation across the subgaleal gliding zone in the direction of the best lifting vector $[1,2]$. To date, a few studies have investigated brow thread-lifting alone. The current study evaluated the underlying basis and the shortterm periorbital parameter changes in Asian patients who underwent a double-needle Poly(Lactic Acid/Caprolactone) (P[LA/CL]) thread lift procedure for brow augmentation.

\section{Approach to brow ptosis}

The brow position is the primary determinant of brow ptosis. As the brow descends below the superior orbital margin, if the upper lid height is less than $10 \mathrm{~mm}$, or when the distance between the center of the pupil and the apex of the brow is less than $2.5 \mathrm{~cm}$, brow ptosis exists [3]. The extent of brow ptosis depends on the distance to which the brow has fallen below the supraorbital rim. In general, there is mild brow ptosis when the disparity between actual and ideal brow position is less than 2 $\mathrm{mm}$, moderate when the distance is between 2 and $4 \mathrm{~mm}$ and marked or severe if the range is more than $4 \mathrm{~mm}$ below the supraorbital rim.

In the absence of recent Botox injection and frontal nerve injury, brow ptosis in the medial to mid-pupil line suggests that the problem is likely related to an upper eyelid problem. However, if the brow ptosis is predominantly lateral to the mid-pupil line, brow ptosis is expected to be brow origin.

Patients typically present to the clinic for treatment of wrinkles in the forehead and glabella, which mostly develop as a result of "compensated brow ptosis," that is, subconscious contraction of the frontalis muscle in adaptation to the "ptotic brow". Botox injection or excision of the upper eyelid skin during surgery will cause temporary, reversible inhibition or permanent removal of the stimuli of this frontalis activation, respectively, resulting in a further brow descent, which can lead to considerable patient distress and dissatisfaction [4].

Another similar but different condition, called dermatochalasis, affects patients with an excess eyelid skin weighed down by gravity, with a prevalence of approximately $61.8 \%$ in Hong Kong [5]. Dermatochalasis differs from eyelid ptosis caused by a weakened levator muscle, and patients may manually elevate the upper eyelid with fingers or with head tilted back at the neck to see under the droopy eyelids.

Revision upper eyelid surgery with excessive removal of the upper eyelid skin in an attempt to correct brow ptosis will often lead to the development of complications, e.g. lagophthalmos, scarring. On the contrary, proper stabilization of the brow position at the time of upper eyelid surgery will prevent these complications and improve the treatment results [6]. Therefore, preoperative identification and correct treatment are vital.

Brow lifting using a suture thread is a simple treatment option with relatively short downtime, compared with traditional open brow lift surgery, complementary to upper eyelid surgery for patients with brow augmentation.

\section{Candidate selection for brow-lifting}

In general, for patients who need more than $1.5 \mathrm{~cm}$ brow elevation, surgery is recommended. Those who require less than $1.5 \mathrm{~cm}$ brow lift, young to middle-aged, good skin elasticity, individuals with few or no frontal wrinkles, a low hairline position are generally good candidates for non-surgical treatment. Patients with thick and compromised skin elasticity, advanced signs of ageing, and thin and fragile skin are inherently not suitable for any thread-lifting procedures [7-9].

\section{Materials and methods}

In a single clinic, between July 2019 and March 2020, 45 patients underwent brow augmentation using absorbable sutures. Only 11 patients with mild to moderate brow ptosis, female, aged between 33 and 69 years (average: 44.0 years) who underwent brow lifting with double-needle P(LA/CL) thread suture alone were included in the analysis. All received 20U of Botox injection to weaken the brow depressors two weeks before thread insertion. Eight patients developed upper blepharoplasty within 6 months.

All thread lift procedures were carried out under local anesthesia in the clinic. Approximately 0.1 to $0.2 \mathrm{ml}$ of Xylestesin-A (3M ESPE, Germany) was injected into each and all of the premarked entry and exit points.

In addition, each patient was given an opportunity to review the protocol of the study and signed the consent for photo release prior to commencement of the study.

\section{Suture design}

The suture thread consists of multiple barbs along with the 50-cm long P(LA/CL) United States pharmacopoeia 2/0 monofilament thread. The double-needle suture has a triangular cutting bevel at both ends of the needle (Fig. 1). One needle labelled as " $\mathrm{A}$ " needle with sharp ends ( $\mathrm{A}^{\prime} \mathrm{A}$ ") and the other tagged as "B" needle with sharp ends ( $\mathrm{B}^{\prime} \mathrm{B}$ "). 


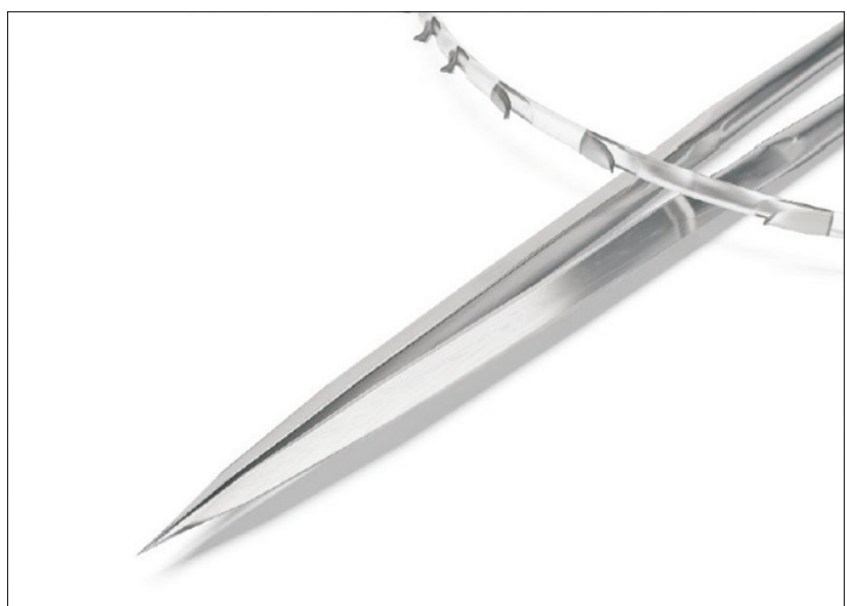

Fig. 1. Showing thread design of each lifting with two double bevel needles.

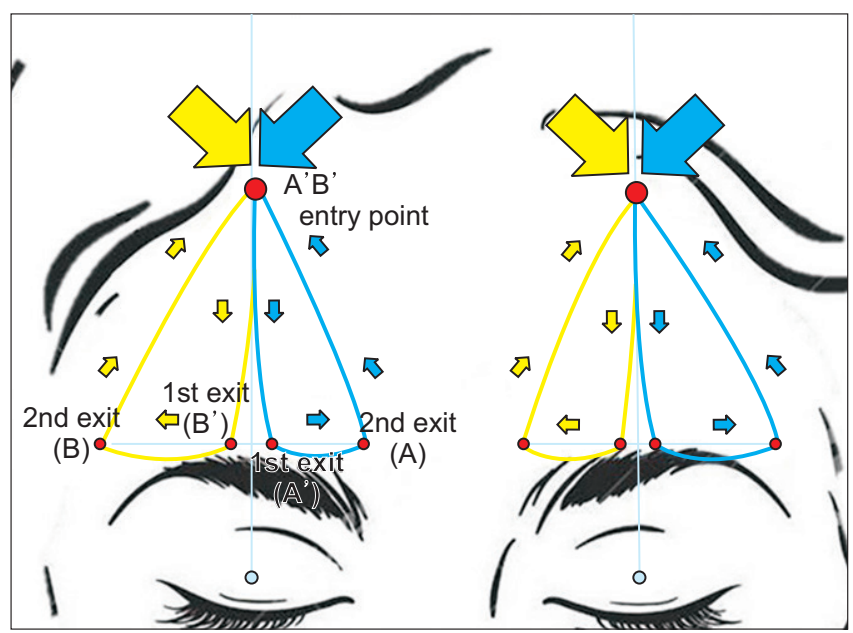

Fig. 2. The use of this diagram has been approved by Aptos. Showing the thread-liftinging pathway design. Each thread is divided into two pathways, one yellow and one blue. The larger arrows on top showing the entry points ( $A^{\prime} B^{\prime}$ entry point). The small arrows (the needle A with A' A" at respective ends and the needle B with B' B" at respective ends) showed the direction of thread passage and various exit points.

\section{Insertion technique}

The double-needle pierced through the skin via the premarked entry point $(*)$ at the level of the hairline. Needle A $\left(A^{\prime}\right)$ followed the blue line within the subgaleal layer toward the mid-brow (Fig. 2). Two-thirds of the needle A (A') pierced through the skin surface at the mid-brow. Needle A (with A") pivoted around 180 degrees and advanced toward the glabellar area (Fig. 3). Needle A (with A') pivoted around the glabellar and up to the original entry point $\left({ }^{*}\right)$ at the hairline (Fig. 4$)$. The second needle (B, B') followed the "mirror-image" pathway

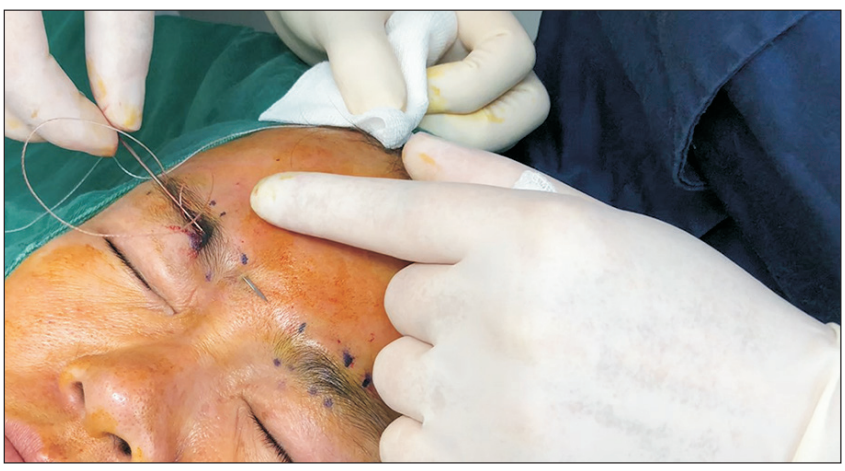

Fig. 3. Showing thread insertion $A^{\prime}$ into and across towards the medial end of the brow.

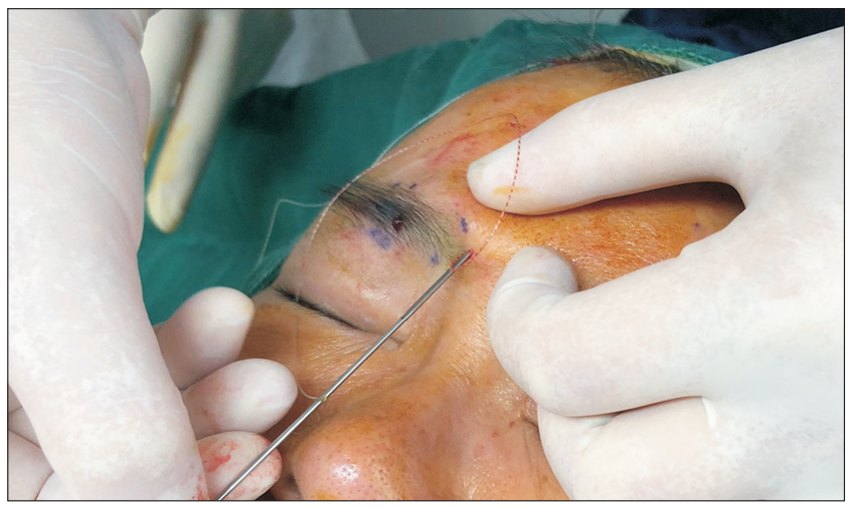

Fig. 4. Showing the thread $A^{\prime}$ advancing from glabellar to original hairline entry point.

(yellow), same as the first needle, but moving from entry point to mid-brow to the lateral end of the brow and back to the entry point (*) (Fig. 2). Ends of suture adjusted with slight hypercorrection of the eyebrows for skin draping (Fig. 3). Excess threads trimmed at the hairline and same technique and design on the other side of the forehead. Antibiotic ointment applied over the skin incision after treatment with intermittent ice-compression over upper face 48 hours following the procedure.

The clinic assistants took photos of the surgical site using a Nikon D 5200 camera (Nikon, Tokyo, Japan) and Mirage 3-dimensional computerized imaging system (Taiwan), at baseline, after treatment, and during follow-up, between 4 and 6 months after thread-lifting (Fig. 5). All observed and reported side effects, as well as complications, were recorded.

Periorbital measurements, before and after the thread lift procedure, were automatically quantified by the imaging system during the photo session. For analysis, the following parameters collected. 

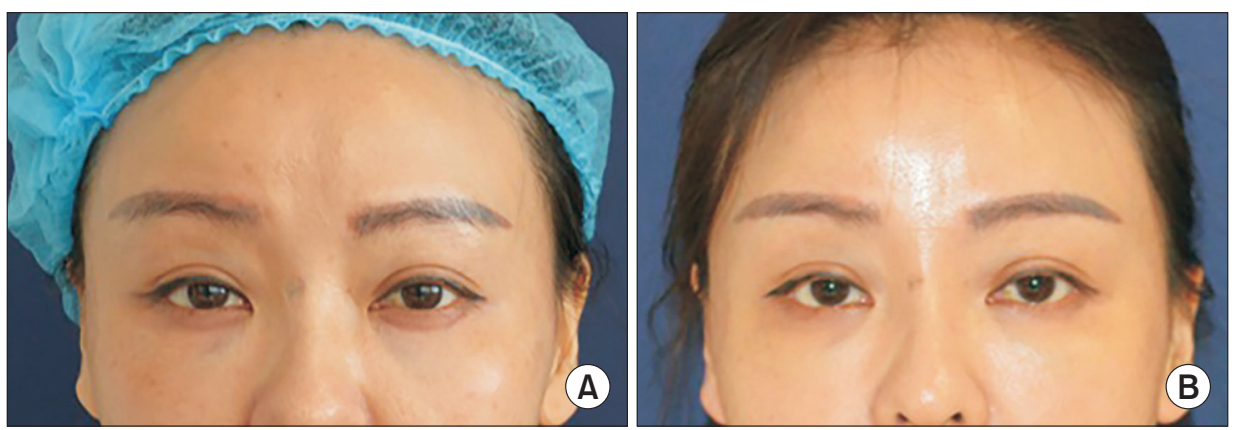

Fig. 5. Patient one before treatment (A) and three months after treatment (B).

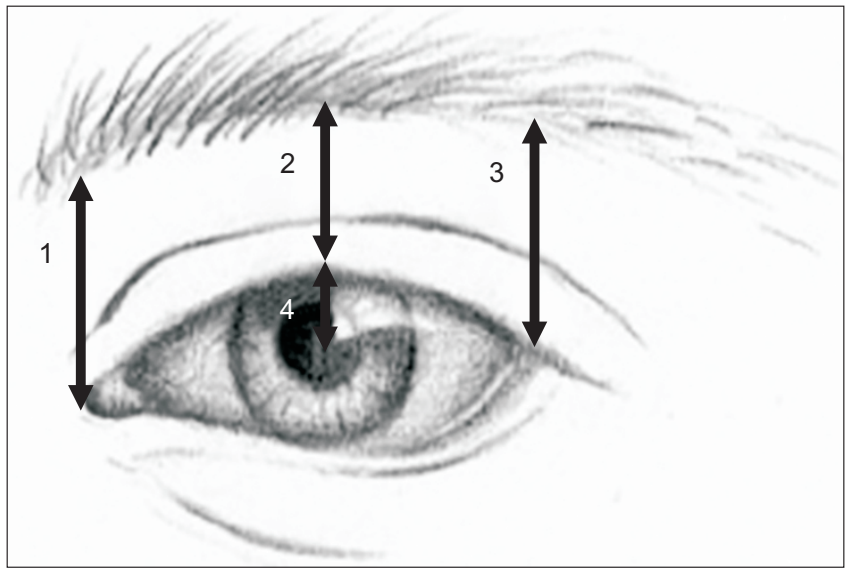

Fig. 6. Showing the measurements between brow and upper eyelid margin (1) nasal eyebrow (NEP), (2) central eyebrow (CEP), (3) temporal eyebrow (TEP).

The data collected for analysis were:

(I) The distance between the upper level of the marginal reflex of the pupil

(1) Medial eyebrow (NEP),

(2) Central eyebrow (CEP), and

(3) Temporal eyebrow (TEP);

(II) The distance between the corneal light reflex and

(1) Brow (brow height [BH]),

(2) Medial canthus, and

(3) Height width; and

(III) the palpebral fissure, which is the sum of the distance between the margin reflex from the corneal light reflex to the upper eyelid margin (MRD1) and the margin reflex distance from the corneal light reflex to the lower eyelid margin (MRD2) (Fig. 6, 7).

Student's t-test conducted to determine if there are significant differences in periorbital dimensions comparing before and after treatment. When comparing follow-up and baseline recordings, if the change in periorbital parameters is less than 2 $\mathrm{mm}$, classified as mild brow lifting and if the difference is more

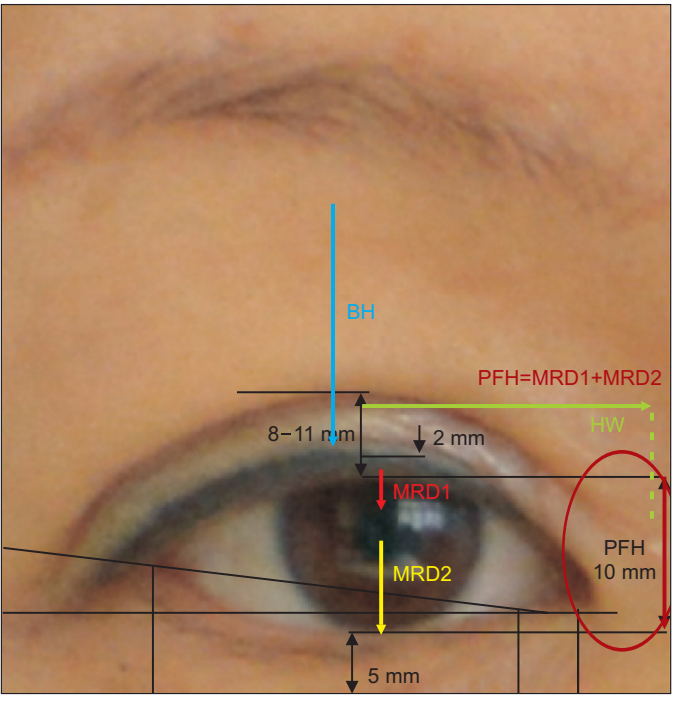

Fig. 7. The diagram showing various measurements between brow and eye. $\mathrm{BH}$ the distance between brow and upper eyelid margin. PFH is the sum of the MRD1 and MRD2. BH, brow height; MRD1, margin reflex distance from the corneal light reflex; MRD2, margin reflex distance from the corneal light reflex to the lower eyelid margin, $\mathrm{PFH}$, palpebral fissure height.

than $2 \mathrm{~mm}$, then classified as moderate brow lifting. The distance variation was compared with the corresponding contralateral sample using Wilcoxon's non-parametric test (wilcoxon signed-rank Test calculator, https://www.socscistatistics.com/ tests/signedranks/default2.aspx).

\section{Results}

Mild brow ptosis is when the actual brow position is less than $2 \mathrm{~mm}$ below the supraorbital rim, and it is moderate if the brow position is 2 to $4 \mathrm{~mm}$ below the supraorbital rim. A total of 11 female patients, with an average age of 44 years (range, 33-69 years), underwent $\mathrm{P}(\mathrm{LA} / \mathrm{CL})$ thread lift for brow augmentation. About a third $(36.7 \%, 4 / 11)$ of the patients had mild brow ptosis and the rest $(63.6 \%, 7 / 11)$ have moderate brow ptosis (Table 1$)$. 
Table 1. Demographics of 11 patients divided into mild and moderate ptosis group

\begin{tabular}{ccc}
\hline \multirow{2}{*}{ Age (yr) } & \multicolumn{2}{c}{ Severity of brow ptosis $(\mathbf{n}=\mathbf{1 1})$} \\
\cline { 2 - 3 } & \multicolumn{1}{c}{ Mild } & Moderate \\
\hline $30-39$ & $2(18.2)$ & $2(18.2)$ \\
$40-49$ & $2(18.2)$ & $1(9.1)$ \\
$50-59$ & $0(0)$ & $2(18.2)$ \\
$60-69$ & $0(0)$ & $2(18.2)$ \\
Total & $4(36.4)$ & $7(63.6)$ \\
\hline
\end{tabular}

Values are presented as $\mathrm{n}(\%)$.

All periorbital measurements (both right and left) obtained after the thread lift procedure showed a significant difference $(\mathrm{p}<0.05)$ compared with those at baseline after to 6 months of follow-up. The extent of lifting is the same and balanced on both sides. The differences were not significant when comparing the right side to the comparable left side.

A higher proportion of patients with moderate brow ptosis achieved at least $2 \mathrm{~mm}$ lifting (moderate lifting) compared with those with mild brow ptosis. Approximately $25 \%$ of patients with mild brow ptosis showed moderate lifting in NEP and TEP, whereas those with moderate brow ptosis exhibited $30 \%$ to $60 \%$ and $45 \%$ to $60 \%$ elevations in NEP and TEP, respectively. Patients with mild brow ptosis showed a $25 \%$ elevation in CEP and BH (Table 2). The following transient side effects occurred: mild bruising, slight discomfort, and dimpling predominantly around the entry/exit points but all resolved in time without permanent sequelae. None of the patients reported wound infection, scarring, or irregularity.

\section{Discussion}

Even though the final resultant eyebrow position was maintained by the "tug-of-war vectors" between antagonizing contractions (elevators and depressors), the imbalance in vectors will trigger the formation of undesirable rhytids in the glabella and forehead. A recent electromyographic study reported that eyebrow positions rely on the "simultaneous activation of opposite muscle groups". The transverse heads of the corrugator supercilii and the lateral aspect of the orbicularis oculi muscles play a significant role in the descent of the lateral brow over the superior orbital rim [4]. With a reduction in motor recruitment in the frontalis and corrugators, the muscular contraction becomes significantly weaker than the preserved recruitment in the orbicularis oculi; therefore, the downward force is a greater than the upward force, leading to sagging of the eyebrows [10]. The descending pull of the brow, exaggerated by gravity, re-
Table 2. Proportion of the change ( $>2 \mathrm{~mm}$ ) in the before and 4 to 6 months after treatment (both right and left) in various periorbital parameters

\begin{tabular}{lcc}
\hline \multicolumn{1}{c}{ Variable $^{*}$} & Mild brow ptosis (\%) & Moderate ptosis (\%) \\
\hline TEP & $25-75$ & $45-60$ \\
CEP & $25-50$ & $\sim 30$ \\
NEP & $25-50$ & $30-60$ \\
PF & 0 & 15 \\
BH & 25 & 15 \\
HW & 25 & 15 \\
\hline
\end{tabular}

*The periorbital measurements referred to the distance between (I) upper eyelid margin of the pupil and (1) temporal eyebrow (TEP), (2) central eyebrow (CEP), (3) nasal eyebrow (NEP); (II) the corneal light reflex and (1) palpebral fissure (PF), (2) brow (BH), (3) medial canthus (HW).

duces the frontalis tone, overactive brow depressors, thereby forcing the unsupported portion of the lateral superficial fascia to pivot on the fixed anchoring points and lateral end of the brow migrate inferomedially, resulting in lateral hooding [7]. The intrinsic anatomical weakness may explain why a higher proportion of patients with moderate brow ptosis achieve moderate brow lift, compared to those with mild brow ptosis. About half (50\%) moderate brow ptosis and $52.5 \%$ mild brow ptosis achieved moderate brow lift in TEP. Moderate lifting was observed in $37.5 \%$ (moderate brow ptosis) and $45 \%$ (mild brow ptosis) of the patients (Table 2).

\section{The latest evidence of thread lifting}

In a systematic review of thread lift studies by Gülbitti et al. (2018) [8], the authors reported that "within the past decade, little or no substantial evidence has been added to the peerreviewed literature to support or sustain the promising statement about thread lift sutures." However, during our examination of these "non-promising" thread lift studies, we discovered that six of the seven studies reviewed were conducted before the year 2015. One study was published in 2015 but carried out before 2015. Furthermore, these "pre-2015" studies evaluated the efficacy of combined treatments, such as, i.e. thread lift with surgery, plasma-rich platelet therapy, and filler injection, rather than that of thread lift alone. Based on their search criteria, a repeat literature search was performed, focusing on studies published in the last 5 years. Also, systemic reviews, case reports, and open surgery studies excluded from the analysis. We found four new studies that evaluated the thread lift treatment alone [9,11-13], and all demonstrated satisfactory results, high patient acceptance, and low complications. Following P(LA/CL) monofilament thread insertion, the progressive formation of fibrous 
tissue was noted around the thread lift sutures that exhibited slow degradation ( $41.1 \%$ over 72 weeks). This fibrotic tissue will continue to sustain the thread lift procedure results but will not negatively impact upon outcome of thread lift procedure [14$16]$.

Volume loss and muscular hyperactivity are the two major factors contributing to ageing eyebrows. Alternative non-surgical brow augmentation procedures include Botox and filler injection, and energy-based devices (e.g., Ulthera and Thermage) are complementary to brow thread lifting for upper face rejuvenation. Botulinum toxin acts by selectively inhibiting brow depressors and reducing tone, resulting in relaxation and unopposed lifting of brow elevators, thereby inducing brow lift and decreasing forehead wrinkles. In younger patients, Botox injection will generally increase the ptotic brow by 1 to $2 \mathrm{~mm}$. Botox with polydioxanone threads can also significantly improve brow position [17]. Dermal and subcutaneous filler substances, such as hyaluronic acid products and biostimulators, act as tissue expanders to provide structural support for soft tissue augmentation.

\section{Conclusion}

Subjective measurements using three-dimensional computerized imaging facilitates the ease and consistency of periorbital parameters before and after the treatment procedures.

Preoperative identification of brow ptosis is essential. Early brow stabilization will prevent the descent of brow tissues following the loss of frontalis contraction stimuli and can cause considerable grief and patient dissatisfaction, especially after upper eyelid surgery. Selecting the right candidate is another vital element for achieving a sufficient brow thread lift. Recent thread lifts studies have demonstrated positive results with high patient satisfaction [16]. Our data suggested that the minimally invasive thread lift procedure can achieve a significant and balanced brow lift.

The multi-modality approach in targeting upper face ageing specifically at contributing factors (facial volume loss, muscular hyperactivity, and soft tissue descent) will enhance treatment outcome. Future long-term prospective studies with a larger population and longer follow-up may be warranted to determine the long-term efficacy of this treatment.

\section{Conflicts of interest}

The authors have nothing to disclose.

\section{References}

1. Liu JH, Trussler AP. Brow lift. Sel Read Plast Sorg 2009;11:1-28.

2. Ramirez OM. The anchor subperiosteal forehead lift. Plast Reconstr Surg 1995;95:993-1003.

3. Kashkouli MB, Abdolalizadeh P, Abolfathzadeh N, Sianati H, Sharepour M, Hadi Y. Periorbital facial rejuvenation; applied anatomy and pre-operative assessment. J Curr Ophthalmol 2017;29:154-68.

4. Knize DM. Anatomic concepts for brow lift procedures. Plast Reconstr Surg 2009;124:2118-26.

5. Mak ST, Kwok SWJJ, Yuen HKL. Prevalence of eyelid diseases among adults in Hong Kong. Hong Kong J Ophthalmol 2018;22:18-21.

6. Hassanpour SE, Khajouei Kermani H. Brow ptosis after upper blepharoplasty: findings in 70 patients. World J Plast Surg 2016;5:58-61.

7. Knize DM. An anatomically based study of the mechanism of eyebrow ptosis. Plast Reconstr Surg 1996;97:1321-33.

8. Gülbitti HA, Colebunders B, Pirayesh A, Bertossi D, van der Lei B. Thread-lift sutures: still in the lift? A systematic review of the literature. Plast Reconstr Surg 2018;141:341e-7e.

9. Kwon HH, Choi SC, Park GH, Jung JY. Clinical evaluations of a novel thread lifting regimen using barbed polyglyconate suture for facial rejuvenation: analysis using a 3-dimensional imaging system. Dermatol Surg 2019;45:431-7.

10. Yun S, Son D, Yeo H, Kim S, Kim J, Han K, et al. Changes of eyebrow muscle activity with aging: functional analysis revealed by electromyography. Plast Reconstr Surg 2014;133:455e-63e.

11. Rezaee Khiabanloo S, Jebreili R, Aalipour E, Saljoughi N, Shahidi A. Outcomes in thread lift for face and neck: a study performed with Silhouette Soft and Promo Happy Lift double needle, innovative and classic techniques. J Cosmet Dermatol 2019;18:84-93.

12. Ali YH. Two years' outcome of thread lifting with absorbable barbed PDO threads: innovative score for objective and subjective assessment. J Cosmet Laser Ther 2018;20:41-9.

13. Ogilvie MP, Few JW Jr, Tomur SS, Teven CM, Semersky AJ, Bruno CR, et al. Rejuvenating the face: an analysis of 100 absorbable suture suspension patients. Aesthet Surg J 2018;38:654-63.

14. Sulamanidze GM, Sulamanidze MA, Sulamanidze KM, Kajaia AA, Giorgadze SG. The subcutaneous tissue reaction on poly (L-lactide-co-caprolactone) based threads. Int J Clin Exp Dermatol 2018;3:1-9. 
15. Adamyan AA, Skuba ND, Sulamanidze MA, Khusnutdinova ZR. Morphological substantiation of facial skin lifting with APTOS threads. International Congress on Plastic, Reconstructive and Aesthetic Surgery;2002; Moscow, Russia. p. 9-10.

16. de Benito J, Pizzamiglio R. Suspension of the gluteal region with silhouette sutures. Aesthet Surg J 2013;33(3 Suppl):82S9S.

17. Kang KJ, Chai CY. Immediate treatment of botulinum toxin type A-induced brow ptosis with polydioxanone cog thread insertion. J Cosmet Med 2017;1:46-51. 